\title{
Monocytopenia with susceptibility to infections
}

INSERM

\section{Source}

INSERM. (1999). Orphanet: an online rare disease and orphan drug data base.

Monocytopenia with susceptibility to infections. ORPHA:228423

Monocytopenia with susceptibility to infections is a rare, genetic, primary

immunodeficiency disorder characterized by profound circulating monocytopenia, B- and

NK-cell lymphopenia and severe dentritic cell decrease, which manifests clinically with

disseminated mycobacterial and viral infections, as well as opportunistic fung al and

parasitic infections and frequent pulmonary alveolar proteinosis. Predisposition to

developping myeloid neoplasms is associated. 